\title{
Compare the Frequency of Wound Infection with Ceftriaxone versus Amoxicillin in females undergoing cesarean section at term
}

\author{
ANEEQA ILYAS ${ }^{1}$, BILAL RAFIQUE MALIK², REHAN ANWAR ${ }^{3}$ \\ 1 Associate Professor of Medicine, Medical Unit-II, Services Hospital Lahore \\ 2Assistant Professor of Medicine, King Edward Medical University Lahore \\ 3Associate Professor Medicine, Sialkot Medical College, Sialkot \\ Correspondence to Dr. Aneeqa Ilyas, Email: Aneeqamansoor@outlook.com
}

\begin{abstract}
Background:Post-caesarean wound infection is a frightful complication of cesarean delivery and increase burden on health care system. Prevention of post-cesarean wound infection must be the priority in any healthcare center in developing countries. Amoxicillin is an antibiotic often used for the treatment of a number of bacterial infections.

Aim: To compare the frequency of wound infection with ceftriaxone versus amoxicillin in females undergoing cesarean section at term

Study design: Randomized Controlled Trial

Setting \& duration: Department of Medicine and Gynecology, SIMS, Lahore from 01-07-2020 to 31-12- 2020.

Methods: After fulfilling the selection criteria, 250 females were enrolled and were divided randomly into two equal groups. Group 1 was given intravenous amoxicillin and group 2 was given intravenous ceftriaxone. Then cesarean was done under spinal anesthesia. Post-op wound infection was noted in all the females. The data was analyzed in SPSS.

Results: The mean age of the females of amoxicillin group was $28.09 \pm 6.01$ years whereas the mean age of the ceftriaxone group females was $29.38 \pm 6.41$ years. The mean gestational age of the females in amoxicillin group was $38.98 \pm 0.85$ weeks whereas the mean gestational age in ceftriaxone group was $38.94 \pm 0.79$ weeks. The mean BMl of the females in amoxicillin group was $26.58 \pm 6.27 \mathrm{~kg} / \mathrm{m} 2$ whereas the mean BMl in ceftriaxone group was $29.32 \pm 6.36 \mathrm{~kg} / \mathrm{m} 2$. The post-cesarean wound infection was found in $2(1.6 \%)$ females in amoxicillin group while in $8(6.4 \%)$ females in ceftriaxone group. This difference was statistically insignificant i.e. pvalue $=0.0 .053$

Conclusion: The amoxicillin is more effective from prevention of post-op wound infection than to ceftriaxone in females underwent cesarean section.

Keywords: Amoxicillin, Ceftriaxone, cesarean section, post-cesarean wound infection
\end{abstract}

\section{INRODUCTION}

Caesarean section wound infections are a significant cost on the health system, and preventing them should be a top focus in poor nations' healthcare ${ }^{1}$. For the past 30 years, an increasing caesarean section rate has been a source of public health concern across the world; its usage has grown to an unreasonable level since 1970. As a result, there will be negative economic and health consequences ${ }^{2}$.

Fear of liability, the health-care system, caesarean section by choice, increasing use of electronic fetal cardiac monitoring, and a higher proportion of breech births by caesarean section are all contributing to the rise in caesarean section rates in industrialized nations. The causes for the rise in caesarean section rates in emerging nations are many. The major factors include poor socioeconomic conditions, low literacy, a lack of basic health care, and certain clinicians' low threshold for caesarean delivery.

Infections at the surgical site are a typical side effect of obstetric and gynecological operations. Antimicrobial prophylaxis during caesarean section has been demonstrated to reduce postoperative morbidity, hospitalization costs, and length of stay ${ }^{3}$. Antibiotics prophylaxis is frequently given before, during, and after a

Received on 29-01-2021

Accepted on 28-05-2021 caesarean operation. Cesarean delivery is one of the most major risk factors for postpartum infection. Infection is more common after a Caesarean section than after a vaginal birth ${ }^{4}$.

So we conducted this trial to compare the wound infection with ceftriaxone versus amoxicillin in females after cesarean section. It is known that amoxicillin is associated with less wound infection. But ceftriaxone is also effective in reducing wound infection. So to get the evidence regarding more efficacious drug, we conducted this trial.

The objective of the study was to compare the frequency of wound infection with ceftriaxone versus amoxicillin in females undergoing cesarean section at term

\section{MATERIALS AND METHODS}

After approval from Ethical Review Board, this randomized controlled trial was conducted in the Department of Medicine and Obstetrics \& Gynecology, Services Hospital, Lahore from $1^{\text {st }}$ July 2020 to $31^{\text {st }}$ December 2020. Sample of 250 cases was estimated by using 95\% confidence level, 5\% anticipated population proportion and percentage of postcesarean wound infection i.e. $20 \%$ after cesarean section. Sample technique used was non probability, consecutive sampling

Inclusion criteria: Females of age 18-40 years, undergoing cesarean section under spinal anesthesia due to $\mathrm{h} / \mathrm{o}$ 
previous cesarean sections, cephalo-pelvic disproportion, and maternal request were included in the trial.

Exclusion criteria: Females with chronic or gestational hypertension $(B P \geq 140 / 90 \mathrm{mmHg})$, diabetes $(2-h$ OGTT $>186$ $\mathrm{mg} / \mathrm{dl}$ ), parity 5 or more, emergency cesarean section, anemia $(\mathrm{Hb}<10 \mathrm{mg} / \mathrm{dl}), \quad I N R>2$ were not included in the study.

Data Collection Procedure: After approval from hospital ethical committee, 250 women fulfilling the inclusion criteria was included. Informed consent was obtained. Demographic data was also obtained. The cesarean section was done under spinal anesthesia by a single surgical team with assistance of researcher. Then females were divided randomly in two groups (125 cases in each group). In group A, 1 gm intravenous amoxicillin was given after cord clamping and repeated after every 24 hours for 72 hours, followed by oral tablet amoxicillin $250 \mathrm{mg}$ thrice a day for 4 days. In group B, $1 \mathrm{gm}$ intravenous ceftriaxone was given after cord clamping and repeated after every 24 hours for 72 hours followed by oral tablet cefuroxime $250 \mathrm{mg}$ thrice a day for 4 days. Females were follow-up in OPD after 10 days. After 10 days, stitches were removed and wound was examined. If there was presence of fever, pain, tenderness, swelling and pus at wound site, then wound infection was labeled. All this data was collected in proforma.

Data analysis: The data was analyzed in SPSS 21. Chisquare test was applied to compare wound infection in both groups. $P$ - value $\leq 0.05$ was taken as significant.

\section{RESULTS}

The mean age of the females of amoxicillin group was 28.09 \pm 6.01 years whereas the mean age of the ceftriaxone group females was $29.38 \pm 6.41$ years. The mean gestational age of the females in amoxicillin group was $38.98 \pm 0.85$ weeks whereas the mean gestational age in ceftriaxone group was $38.94 \pm 0.79$ weeks. The mean BMl of the females in amoxicillin group was $26.58 \pm 6.27 \mathrm{~kg} / \mathrm{m}^{2}$ whereas the mean $\mathrm{BMI}$ in ceftriaxone group was $29.32 \pm 6.36 \mathrm{~kg} / \mathrm{m}^{2}$. In Amoxicillin group, there were 38 primigravida, 12 had parity 1,29 had parity 2, 29 had parity 3 and 17 had parity 4 . In ceftriaxone group, there were 21 primigravida, 23 had parity 1,34 had parity 2, 30 had parity 3 and 17 had parity 4 (Table 1).

According to this trial, the post-cesarean wound infection was found in $2(1.6 \%)$ females in amoxicillin group while in $8(6.4 \%)$ females in ceftriaxone group. This difference was statistically insignificant i.e. $p$-value $=0.0 .053$ (Table 2).

We stratified data for age of females. In females aged $<30$ years, the post-cesarean wound infection rate was similar in both groups i.e. $5(3.3 \%)$ vs. $2(1.6 \%)$, but in females aged $\geq 30$ years, the post-cesarean wound infection rate was significantly less with amoxicillin i.e. $0 \%$ vs. $10.7 \%$ $(p<0.05)$. There was no impact of gestational age on effectiveness of both drugs in reducing the post-cesarean wound infection rate. Results were also insignificant for parity of females. While for BMI, there was no female who develop post-cesarean wound infection whether she was underweight or had normal BMI, but wound infection was observed in overweight \& obese females, although the difference was insignificant ( $p>0.05)$ (Table 3).
Table 1: Demographics of females in both groups

\begin{tabular}{|l|c|c|}
\hline \multirow{2}{*}{\multicolumn{2}{|c|}{}} & \multicolumn{2}{|c|}{ Study Groups } \\
\cline { 2 - 3 } & Amoxicillin & Ceftriaxone \\
\hline $\mathrm{n}$ & $\mathbf{1 2 5}$ & $\mathbf{1 2 5}$ \\
\hline Age (years) & $28.09 \pm 6.01$ & $29.38 \pm 6.41$ \\
\hline Gestational age (weeks) & $38.98 \pm 0.85$ & $38.94 \pm 0.79$ \\
\hline BMl & $26.58 \pm 6.27$ & $29.32 \pm 6.36$ \\
\hline Parity & 38 & 21 \\
\hline Primigravida & 12 & 23 \\
\hline Parity 1 & 29 & 34 \\
\hline Parity 2 & 29 & 30 \\
\hline Parity 3 & 17 & 17 \\
\hline Parity 4 & \multicolumn{2}{|c|}{} \\
\hline
\end{tabular}

Table 2: Comparison of post-cesarean wound infection in both groups

\begin{tabular}{|l|c|c|c|}
\hline \multirow{2}{*}{$\begin{array}{l}\text { Post-op wound } \\
\text { infection }\end{array}$} & \multicolumn{2}{|c|}{ Study Groups } & \multirow{2}{*}{ Total } \\
\cline { 2 - 3 } & Amoxicillin & Ceftriaxone & \\
\hline Yes & $2(16 \%)$ & $8(6.4 \%)$ & $10(4 \%)$ \\
\hline No & $123(98.4 \%)$ & $117(93.6 \%)$ & $240(96 \%)$ \\
\hline Total & $125(100 \%)$ & $125(100 \%)$ & $250(100 \%)$ \\
\hline
\end{tabular}

$P$ value 0.053

Table 3: Comparison of post-cesarean wound infection in both groups stratified for effect modifiers

\begin{tabular}{|c|c|c|c|c|c|}
\hline \multirow{2}{*}{\multicolumn{2}{|c|}{$\begin{array}{c}\text { Post-op } \\
\text { Wound Infection } \\
\end{array}$}} & \multicolumn{2}{|c|}{ Study Groups } & \multirow{2}{*}{ Total } & \multirow{2}{*}{$p$-value } \\
\hline & & Amoxicillin & Ceftriaxone & & \\
\hline \multicolumn{6}{|c|}{ Age (years) } \\
\hline \multirow{2}{*}{$\leq 30$} & Yes & $5(3.3 \%)$ & $2(1.6 \%)$ & $7(2.5 \%)$ & \multirow[b]{2}{*}{0.34} \\
\hline & No & $145(96.7 \%)$ & $127(98.4 \%)$ & $272(97.5 \%)$ & \\
\hline \multirow{2}{*}{$>30$} & Yes & $0(0 \%)$ & $12(10.7 \%)$ & $12(5.9 \%)$ & \multirow{2}{*}{0.001} \\
\hline & No & $91(100 \%)$ & $100(8$ & 191 & \\
\hline \multicolumn{6}{|c|}{ Gestational age (weeks) } \\
\hline \multirow{2}{*}{38} & Yes & $3(3.3 \%)$ & $5(6.5 \%)$ & $8(4.8 \%)$ & \multirow[b]{2}{*}{0.340} \\
\hline & No & $87(96.7 \%)$ & $72(93.5 \%)$ & $159(95.2 \%)$ & \\
\hline \multirow{2}{*}{39} & Yes & $0(0 \%)$ & $4(4.6 \%)$ & $4(2.4 \%)$ & \multirow{2}{*}{0.123} \\
\hline & No & $77(100 \%)$ & $83(95.4 \%)$ & $160(97.6 \%)$ & \\
\hline \multirow{2}{*}{40} & Yes & $2(2.7 \%)$ & $5(6.5 \%)$ & $7(4$ & \multirow{2}{*}{0.443} \\
\hline & No & $72(97.3 \%)$ & $72(93.5 \%)$ & $144(95$ & \\
\hline \multicolumn{6}{|l|}{ Parity } \\
\hline \multirow{2}{*}{ Parity $\leq 1$} & Yes & $1(0.9 \%)$ & $1(1$ & & \multirow[b]{2}{*}{0.827} \\
\hline & No & $105(99.1 \%)$ & $77(98.7 \%)$ & $182(98.9 \%)$ & \\
\hline \multirow{2}{*}{ Multiparity } & Yes & $4(3.0 \%)$ & $13(8.0 \%)$ & $17(5$ & \multirow[b]{2}{*}{0.080} \\
\hline & No & $131(97 \%)$ & $150(92 \%)$ & 281( & \\
\hline \multicolumn{6}{|l|}{ BMI } \\
\hline \multirow{2}{*}{ Underweight } & Yes & $0(0.0 \%)$ & $0(0$ & & \multirow[b]{2}{*}{ NA } \\
\hline & No & $10(100 \%)$ & $9(1$ & 19 & \\
\hline \multirow{2}{*}{ Normal } & Yes & $0(0.0 \%)$ & $0(0.0 \%)$ & $0(0.0 \%)$ & \multirow[b]{2}{*}{ NA } \\
\hline & No & $47(100 \%)$ & $25(100 \%)$ & $72(100 \%)$ & \\
\hline \multirow{2}{*}{$\begin{array}{c}\text { Overweight } \\
\text { \& Obese }\end{array}$} & Yes & $2(2.9 \%)$ & $8(8.8 \%)$ & $10(63 \%)$ & \multirow{2}{*}{0.133} \\
\hline & No & $66(97.1 \%)$ & $83(91.2 \%)$ & $149(93.7 \%)$ & \\
\hline
\end{tabular}

\section{DISCUSSION}

Caesarean section rate average $>20 \%$ in developed world and have similar percentage of hospital deliveries in developing countries, Infectious complications following caesarean section include fever, wound infection, endometritis, bacteraemia, other serious infection and urinary tract infection. Resistance system against bacterium may occur and contribute to the development of wound infections by allowing bacteria to avoid the action of antibiotics given as a preventative measure. In order to create an appropriate antibiotic policy, it is necessary to first identify the local antibiotic susceptibility patterns in a community ${ }^{5,6}$.

When compared to vaginal birth, a Caesarean section carries a five to twenty-fold higher risk of infection. Unnecessary caesarean sections should be avoided since 
they are linked to an increased risk of iatrogenic preterm. Urinary tract infections, surgical site infections, and infections of the pelvic organs are the most frequent postoperative infections after a caesarean section ${ }^{5}$.

Patients should be treated with a broad-spectrum antibiotic at first, with the antibiotic being narrowed down following the results of the culture sensitivity test. Antibiotics should be taken until all clinical signs of infection have disappeared, which takes around 5-7 days. The wound can then be left to seal naturally or, if healthy granulation tissue is visible at the wound's base, the margins of the incision can be re-aproximated using sutures. Parenteral antibiotics should be given until the patient is feverish and asymptomatic for at least 24 hours $^{6}$.

Numerous treatments have been shown to reduce the incidence of infection following major pelvic surgery. Prior to surgery, individuals with pre-existing medical conditions should be stabilized. Second, lengthy preoperative hospitalization should be avoided to the maximum degree feasible to reduce the patient's chance of becoming colonized with hospital-acquired germs ${ }^{7}$.

In this study we compare the ceftriaxone versus amoxicillin in females undergoing cesarean section at term in terms of post-op wound infection. In our study the wound infection was found in 19 (3.94\%) patients, in which post-op wound infection in amoxicillin group noted in $5(2.07 \%)$ patients and it was found in ceftriaxone group in $14(5.81 \%)$ patients. So according to this study results the amoxicillin group showed significantly better result in terms of post-op wound infection than to ceftriaxone group i.e. $p$ value $=0.035$. A study by Ibrahim $W H$ et al in 2011 resulted that with amoxicillin, the reported frequency of wound infection was $1 \%$ administered prophylaxisly at time of cord clamping ${ }^{8}$.

A study by Ujah et al., ${ }^{9}$ in their trial, observed that out of 35 healthy women undergoing elective lower segment cesarean surgery, the effectiveness of intravenous amoxicillin-clavulanic acid (Augmentin) in avoiding postcesarean section infections was investigated. Before the procedure, Augmentin or a placebo was given intravenously. In terms of patient characteristics and operation factors, both groups were equivalent. There were no postoperative febrile or infectious morbidity in the Augmentin group.

Those in this group spent fewer days in the hospital than patients in the placebo group. In terms of post-op surgical site infection different studies presented that if females want to take oral therapy, then $875 \mathrm{mg}$ amoxicillinclavulanate can be given two times a day, or $500 \mathrm{mg}$ cephalexin four times a day (every 6 hours) or $500 \mathrm{mg}$ cefuroxime two times a day are suitable options ${ }^{10,11}$. It has been reported that with ceftriaxone the wound infection was developed in $0.7 \%$ females administered prophylaxisly at time of cord clamping during cesarean section ${ }^{12}$. But another study showed that with ceftriaxone the wound infection was developed in $4.8 \%$ females after cesarean section $^{13}$.
Ruby Kumari et $\mathrm{al}^{14}$ conducted a study on "To study the effectiveness of prophylactic use of ceftriaxone (single dose) in caesarean section in low risk patients in a tertiary care center, Moradabad, India". The author concluded that Ceftriaxone should use as prophylactic antibiotic in patients undergoing for lower segment caesarean section (in low risk cases). Similarly one more study by Alekwe et al., ${ }^{15}$ documented that single dose of ceftriaxone was equally effective as the combined dose of ampiclox, metronidazole and gentamicin, to avoid the development of post-cesarean wound infections. Alekwe et al., did not found significant difference in occurrence of wound infections (7\% vs. $8 \%)$, febrile morbidity ( $7 \%$ vs. $6 \%$ ), and peritonitis (0\% vs. $0 \%$ ).

\section{CONCLUSION}

This present study results concluded that the amoxicillin drug is more effective from prevention of post-op wound infection than to ceftriaxone drug in females undergoing cesarean section at term.

\section{REFERENCES}

1. Nwankwo E, Ibeh I, Enabulele O. Incidence and risk factors of surgical site infection in a tertiary health institution in Kano, Northwestern Nigeria. Int J Infect Control 2012;8(4):8-13.

2. PáduaKSd, Osis MJD, Faúndes A, Barbosa AH, Moraes Filho OB. Factors associated with cesarean sections in Brazilian hospitals. Revista de Saúde Pública 2010;44(1):70-9.

3. Clifford V, Daley A. Antibiotic prophylaxis in obstetric and gynaecological procedures: a review. Australian and New Zealand Journal of Obstetrics and Gynaecology 2012;52(5):412-9.

4. Liu R, Lin L, Wang D. Antimicrobial prophylaxis in caesarean section delivery. Experimental and therapeutic medicine 2016;12(2):961-4

5. Gur R, Duggal SD, Rongpharpi SR, Srivastava R, Kumar A, Gupta V, et al. Post caesarean surgical site infections. Archives of clinical microbiology 2015;6(1).

6. Hofmeyr GJ, Smaill FM. Antibiotic prophylaxis for cesarean section. Cochrane database of Systematic reviews 2002(3).

7. Patrick Duff. Diagnosis and Management of Postoperative Infection. 2019 [cited 2019]; Available from: https://www.glowm.com/resources/glowm/cd/pages/v1/v1c047.html.

8. Ibrahim WH, Makhlouf AM, Khamis MA, Youness EM. Effect of prophylactic antibiotics (Cephalosporin versus Amoxicillin) on preventing post caesarean section infection. Journal of American Science 2011;7(5).

9. Ujah I, Olarewaju R, Otubu J. Prophylactic amoxicillin-clavulanic acid in elective cesarean section. Current therapeutic research 1992;52(5):647-51.

10. Duff P. Antibiotic selection in obstetric patients. Infectious Disease Clinics 1997;11(1):1-12

11. Duff P. Antibiotic selection in obstetrics: making cost-effective choices. Clinical obstetrics and gynecology 2002;45(1):59-72.

12. Kalaranjini $\mathrm{S}$, Veena $\mathrm{P}$, Rani R. Comparison of administration of single dose ceftriaxone for elective caesarean section before skin incision and after cord clamping in preventing post-operative infectious morbidity. Archives of gynecology and obstetrics 2013;288(6):1263-8.

13. Khatun M SS, Khandkar H, Hamid T, Hasan M. Effects of Ceftriaxone and, Age;1(2.02):170-1.55. GfAPoCS.

14. Ruby Kumari, Arti Sharma, Sheetal, Pratibha Roy, Anupriya. To study the effectiveness of prophylactic use of ceftriaxone (single dose) in caesarean section in low risk patients in a tertiary care center, Moradabad, India. Int J Res Med Sci 2017;5(12):5278-82.

15. Alekwe L, Kuti O, Orji E, Ogunniyi S. Comparison of ceftriaxone versus triple drug regimen in the prevention of cesarean section infectious morbidities. The Journal of Maternal-Fetal \& Neonatal Medicine 2008;21(9):638-42 